\title{
Detection of Drift Effects before Calculating the Standard Deviation as a Measure of Analytical Imprecision
}

\author{
By R. Haeckel and B. Schneider \\ Institut für Klinische Chemie und Department für Biometrie und Statistik \\ Medizinische Hochschule Hannover
}

(Received December 4, 1980/May 27, 1982/January 24, 1983)

Summary: The sample standard deviation is commonly used as a measure of analytical imprecision, calculated from a series of $\mathbf{n}$ data obtained from one sample split for $\mathbf{n}$ assays. Drift effects cause an overestimation and consequently a misinterpretation of the standard deviation in clinical chemistry.

The r-ratio test is recommended as a simple procedure for detecting drift effects. It has been found necessary to eliminate outliers before drift effects can be recognized.

\section{Erkennung von Drifteffekten bei der Berechnung der Standardabweichung als Maß der analytischen Präzision}

Zusammenfassung: Die empirische Standardabweichung wird meistens als Maß für die analytische Präzision aus einer Serie von $\mathbf{n}$ Ëgebnissen berechnet, die von einer für $n$ Untersuchungen gesplitteten Probe ermittelt werden.

Drifțeffekte bewirken eine Ưberschätzung und daraus folgend möglicherweise eine Fehlinterpretation der Standardabweichung in der Klinischen Chemie.

Der r-ratio Test wird als ein einfaches Vèrfahren żur Erkennung von Drifteffekten in Abwesenheit von Ausreißern empfohlen.

\section{Intrọduction}

The standard deviation is usually determined as a measure of within-run or between-days imprecision from a set of data. This implies that the data of the run or for the various days can be considered as real= isations of independently and identically distributed (e. g. normally distributed) random variables with finite mean $\mu$ and variance $\sigma^{2}$. This assumption is usually made if the imprecision of analytical procedures is estimated in clinical chemistry without further proof.

Deviation from normal distribution can be easily detected by estimating skewness and excess. For normally distributed samples the absolute value of the skewness is (with probability 0.95 ) less than $1.96 \sqrt{6 / n}$, the excess less than $1.96 \sqrt{24 / n}$ for sufficiently high $n$, e.g. $n>10$. Other tests are more complicated and are described in most statistical textbooks. For instance the Kolmogoroff-Smirnoff or the Lilleford test are well known $(1,2)$. However, these tests have not proved useful in the examples presented here.

In the presence of drift effects (i. e. varying mean values $\mu$ and constant variance $\sigma^{2}$ ) the sample variance

$$
s^{2}=\frac{1}{n-1} \cdot \Sigma\left(x_{i}-x\right)^{2}
$$

overestimates the population variance $\sigma^{2}$. Drift effects may alter the data distribution either in the same direction (unidirectional) or in different directions (e. g. bidirectional fluctuations). They are especially relevant, if the within-run imprecision is calculated from a run of $\mathbf{n}$ data obtained from one specimen split into $\mathbf{n}$ assays. The part of a run, in which drift effects can be neglected, is called a segment (3). In practice, recalibration is not performed during 
one analytical run. Within-run imprecision should be determined within a segment and, in the ideal case, in the absence of drift effects.

In the following, a simple statistical procedure that detects significant drift effects, and some of its experimental applications are described.

\section{Methods}

An Eppendorf analyser 5040 (serial No. D 082/01, Eppendorf Gerätebau GmbH, D-2000 Hamburg) and an ACA model II (serial No. 1330) were applied with a heating control unit adapted to an incubation temperature of $30^{\circ} \mathrm{C}$ (Du Pont de Nemours, Wilmington, Delaware, USA).

The operating and calibration procedures recommended by the manufacturers were strictly followed. Further details are reported elsewhere $(4,5)$.

\section{Statistical Procedures}

Ratio of the mean square successive difference to the variance

It is assumed that the data $x_{i}$ are realisations of independent random variables with identical variance $\sigma^{2}$. The quantity $q^{2}$ is half the mean square successive difference:

$$
q^{2}=\frac{1}{2(n-1)} \sum_{i=1}^{n-1}\left(x_{i+1}-x_{i}\right)^{2}
$$

Under the assumption that at least the successive pairs $\left(x_{i}, x_{i-1}\right)$ have the same mean value $\mu_{i}(i=1,3,5, \ldots)$, the quantity $q^{2}$ is an unbiased estimate of the variance $\sigma^{2}$.

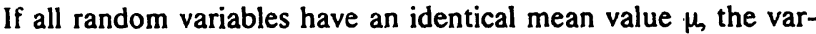
iance $\sigma^{2}$ is estimated by the usual formula

with

$$
s^{2}=\frac{1}{n-1} \sum_{i=1}^{n}\left(x_{i}-\bar{x}\right)^{2}
$$

$$
\bar{x}=\frac{1}{n_{i}} \sum_{i=1}^{n} x_{i}
$$

The estimate $\mathrm{s}^{2}$ is much more sensitive to gradual changes in the population mean, such as drift effects, than is the estimate $q^{2}$, since the $q^{2}$ includes only the difference between successive values. In the absence of drift effects, the ratio

$$
r=\frac{q^{2}}{s^{2}}
$$

should be close to 1.0. In the presence of drift effects, it decreases significantly. Some fractiles in the distribution of $\mathrm{r}$ are given in table 1 for a probability of 5 per cent $(6,7)$, assuming normally distributed random variables.

\section{Test for outliers}

An "outlier" in a series of $n$ measurements $x_{i}(i=1-n)$ is an extremely high or low value outside of the tolerance interval (for a given tolerance probability $p=1-\alpha$, e.g. 0.95 ) for all measurements within the sample.

If the measurements are assumed as realisation of $\mathbf{n}$ independent and identical normally distributed random variables, a tolerance interval for all sample values is given by

$$
\begin{gathered}
x_{\max }-\bar{x} \leqslant s \cdot k_{n, \alpha} \\
\bar{x}-x_{\min } \geqslant s \cdot k_{n, \alpha}
\end{gathered}
$$

where $\mathrm{k}_{\mathrm{na}}$ is a tolerance factor dependent on the sample size $\mathrm{n}$ and chosen tolerance probability $1-\alpha$;

$$
s=\sqrt{\frac{1}{n-1}\left(x_{i}-\bar{x}\right)^{2}}
$$

is the sample standard deviation. The tolerance factor $k_{n, \alpha}$ can be calculated by the formula

$$
k_{n, \alpha}=\sqrt{1-\frac{1}{n}} t\left(1-\frac{\alpha}{n}\right)
$$

where

$$
t\left(1-\frac{\alpha}{n}\right)
$$

is the $1-\frac{\alpha}{n}$

quantile of the $t$-distribution for $n=1$ degrees of freedom.

This test is identical with the Nalimov test described by others $(8-11)$. According to this test a significant outlier should be suspected if a value is at or outside the range :

$$
\begin{aligned}
& \bar{x} \pm 2.385 \cdot s(\text { for } n=20), \text { resp. } \\
& \bar{x} \pm 2.3749 \cdot s(\text { for } n=19 \text { ). }
\end{aligned}
$$

For small values of $n(n \leqslant 25)$ Dixon has described an alternative test $(12-14)$.

\section{Results}

The within-run imprecision was measured with an Eppendorf analyser 5040 for determination of creatine kinase activity on two different days (fig. $1 \mathrm{a}, \mathrm{b}$ ). The data presented in figure $1 \mathrm{a}$ appear to be normally distributed around the mean value. The r-value was close to 1.0 (tab. 1).

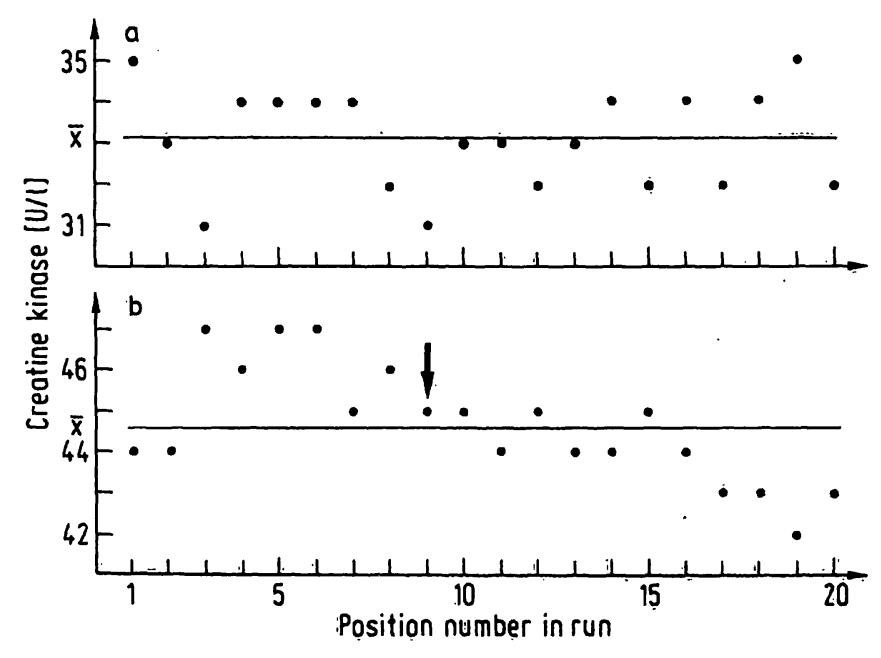

Fig. 1. Run of 20 determinations of the creatine kinase activity in one pool of Moni-trol I control serum with an ACP 5020 on 2 different days $(a, b)$. Further details are reported elsewhere (3). 
Tab. 1. 5\%-fractiles in the distribution of

$$
\mathrm{r}=\frac{\mathrm{q}^{2}}{\mathrm{~s}^{2}}
$$

(according to 1.c. (6), for normally distributed random variables.

\begin{tabular}{ll}
\hline $\mathrm{n}$ & $\mathrm{r}_{5 \%}$ \\
\hline 4 & 0.390 \\
5 & 0.410 \\
6 & 0.445 \\
7 & 0.468 \\
8 & 0.491 \\
9 & 0.512 \\
10 & 0.531 \\
11 & 0.548 \\
12 & 0.564 \\
13 & 0.578 \\
14 & 0.591 \\
15 & 0.603 \\
16 & 0.614 \\
17 & 0.624 \\
18 & 0.633 \\
19 & 0.642 \\
20 & 0.650 \\
\hline
\end{tabular}

In figure $1 \mathrm{~b}$ a distinct downward trend can be easily noticed. The $r$-ratio (tab. 2 ) significantly suggested a trend effect. The reason for this phenomenon has been investigated; furthermore, it was not observed when the experiment was repeated several times.
The data from figure 1a were taken to simulate a unidirectional trend by adding $5 \%$ increments of 1,2 or 3 fold standard deviation (e. g. $5 \%$ of $1 \mathrm{~s}$ to $\mathrm{x}_{1}$, $10 \%$ of $1 \mathrm{~s}$ to $\mathrm{x}_{2}, 15 \%$ of $1 \mathrm{~s}$ to $\mathrm{x}_{3}$ and so on). Visually a distinct trend was noticed if a total increment of 3 standard deviations was used (fig. $2 d$ ).

When an increment of 2 standard deviations was applied, the trend was barely apparent from the visual inspection (fig. 2c), whereas with 1 standard deviation a normal distribution would be assumed by most observers (fig. 2b). The r-ratio (tab. 1) suggested a significant trend only with the data shown in figure $2 c$.

A similar simulation study is shown in figure 3 and table 2.

In further experiments the within-run imprecision for the determination of the bilirubin and phosphate concentration with an ACA was studied. With bilirubin, the within-run imprecision was as high as the between-days imprecision: The r-ratio suggested a significant trend. This phenomenon can easily be interpreted as fluctuations, when using a graphical presentation of the single values on the usual control chart (fig. 4).

These fluctuations of the bilirubin values were probably caused by slight temperature variations and

Tab. 2. r-ratio calculated for several examples. The data from figures $1-5$ are used.

\begin{tabular}{|c|c|c|c|c|c|c|c|}
\hline $\begin{array}{l}\text { Data from } \\
\text { figure }\end{array}$ & Assumption from visual inspection & $r=\frac{q^{2}}{s^{2}}$ & $\bar{y}$ & $\mathbf{s}_{\mathbf{y}}$ & $\overline{\mathbf{x}}$ & $\mathbf{a}$ & b \\
\hline $\begin{array}{l}1 \mathrm{a} \\
1 \mathrm{~b}\end{array}$ & $\begin{array}{l}\text { normally distributed } \\
\text { unidirectional drifting }\end{array}$ & $\begin{array}{l}0.99 \\
0.32\end{array}$ & $\begin{array}{l}33.10 \\
44.65\end{array}$ & $\begin{array}{l}1.21 \\
1.42\end{array}$ & $\begin{array}{l}10.5 \\
10.5\end{array}$ & $\begin{array}{l}33.21 \\
46.39\end{array}$ & $\begin{array}{l}-0.01 \\
-0.17\end{array}$ \\
\hline $\begin{array}{l}2 b \\
2 c \\
2 d\end{array}$ & $\begin{array}{l}\text { unidirectional drifting }(+1 \mathrm{~s}) \\
\text { unidirectional drifting }(+2 \mathrm{~s}) \\
\text { unidirectional drifting }(+3 \mathrm{~s})\end{array}$ & $\begin{array}{l}0.86 \\
0.73 \\
0.58\end{array}$ & $\begin{array}{l}33.73 \\
34.36 \\
34.99\end{array}$ & $\begin{array}{l}1.24 \\
1.37 \\
1.57\end{array}$ & $\begin{array}{l}10.5 \\
10.5 \\
10.5\end{array}$ & $\begin{array}{l}33.21 \\
33.21 \\
33.21\end{array}$ & $\begin{array}{l}0.05 \\
0.11 \\
0.17\end{array}$ \\
\hline $\begin{array}{l}3 \mathrm{a} \\
3 \mathrm{~b} \\
3 \mathrm{c} \\
3 \mathrm{~d}\end{array}$ & $\begin{array}{l}\text { normally distributed } \\
\text { unidirectional drifting }(+1 s) \\
\text { unidirectional drifting }(+2 s) \\
\text { unidirectional drifting }(+3 s)\end{array}$ & $\begin{array}{l}0.95 \\
0.79 \\
0.65 \\
0.50\end{array}$ & $\begin{array}{l}327.00 \\
336.11 \\
345.00 \\
354.00\end{array}$ & $\begin{array}{l}17.74 \\
19.29 \\
22.21 \\
26.03\end{array}$ & $\begin{array}{l}10.0 \\
10.0 \\
10.0 \\
10.0\end{array}$ & $\begin{array}{l}322.91 \\
321.72 \\
320.91 \\
319.91\end{array}$ & $\begin{array}{l}0.41 \\
1.44 \\
2.41 \\
3.41\end{array}$ \\
\hline 4 & fluctuating & 0.24 & 54.95 & 2.61 & 10.5 & 56.09 & -0.11 \\
\hline $5 a$ & $\begin{array}{l}\text { outlier included } \\
\text { after exclusion of outlier }\end{array}$ & $\begin{array}{l}1.15 \\
0.54\end{array}$ & $\begin{array}{l}1.0520 \\
1.0542\end{array}$ & $\begin{array}{l}0.0167 \\
0.0139\end{array}$ & $\begin{array}{l}10.5 \\
10.0\end{array}$ & $\begin{array}{l}1.0559 \\
1.0604\end{array}$ & $\begin{array}{l}-0.00038 \\
-0.00061\end{array}$ \\
\hline $5 \mathrm{~b}$ & $\begin{array}{l}\text { as figure } 5 \mathrm{a}+\text { continuously } \\
\text { drifting }(+1 \mathrm{~s}) \\
\text { after exclusion of outlier }\end{array}$ & $\begin{array}{l}1.11 \\
0.51\end{array}$ & $\begin{array}{l}1.0609 \\
1.0632\end{array}$ & $\begin{array}{l}0.0166 \\
0.0133\end{array}$ & $\begin{array}{l}10.5 \\
10.5\end{array}$ & $\begin{array}{l}1.0571 \\
1.0615\end{array}$ & $\begin{array}{l}0.00036 \\
0.00017\end{array}$ \\
\hline $5 \mathrm{c}$ & $\begin{array}{l}\text { as figure } 5 \mathrm{a}+\text { continuously } \\
\text { drifting }(+2 \mathrm{~s}) \\
\text { after exclusion of outlier }\end{array}$ & $\begin{array}{l}0.97 \\
0.45\end{array}$ & $\begin{array}{l}1.0707 \\
1.0732\end{array}$ & $\begin{array}{l}0.0184 \\
0.0151\end{array}$ & $\begin{array}{l}10.5 \\
10.0\end{array}$ & $\begin{array}{l}1.0569 \\
1.0613\end{array}$ & $\begin{array}{l}0.00131 \\
0.00119\end{array}$ \\
\hline $5 d$ & $\begin{array}{l}\text { as figure } 5 \mathrm{a}+\text { continuously } \\
\text { drifting }(+3 \mathrm{~s}) \\
\text { after exclusion of outlier }\end{array}$ & $\begin{array}{l}0.75 \\
0.31\end{array}$ & $\begin{array}{l}1.0801 \\
1.0827\end{array}$ & $\begin{array}{l}0.0210 \\
0.0180\end{array}$ & $\begin{array}{l}10.5 \\
10.0\end{array}$ & $\begin{array}{l}1.0574 \\
1.0616\end{array}$ & $\begin{array}{l}0.00216 \\
0.00210\end{array}$ \\
\hline
\end{tabular}




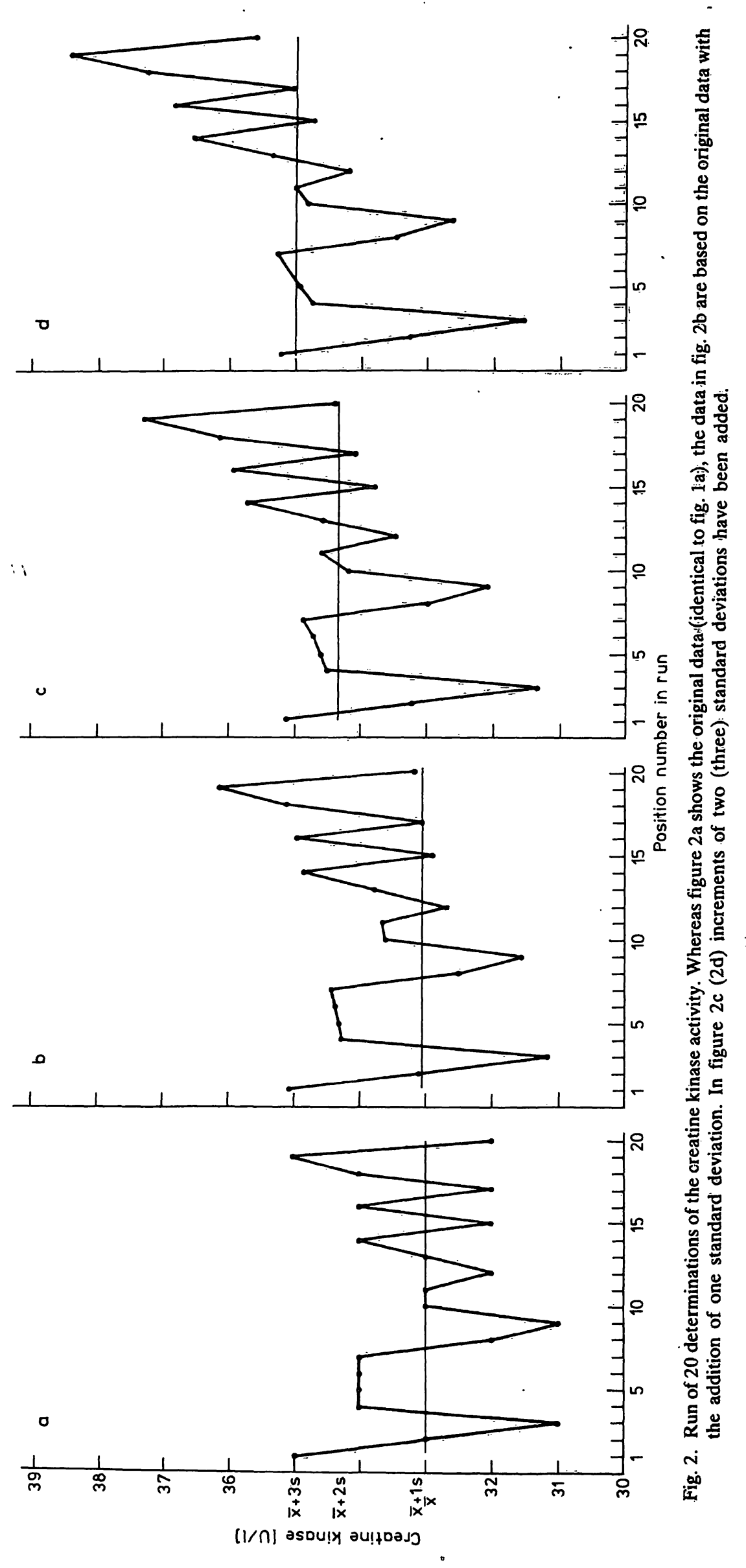

J. Clin. Chem. Clin. Biochem. / Vol. 21, 1983 / No. 8 

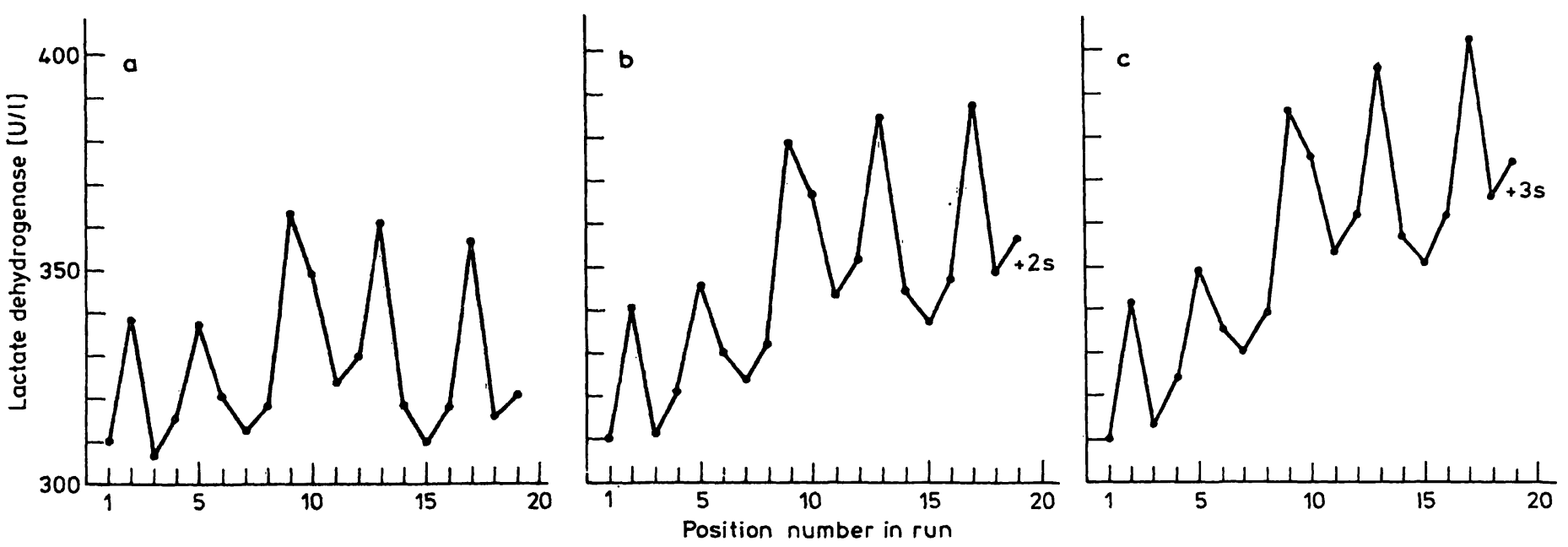

Fig. 3. Run of 19 determinations of the lactate dehydrogenase activity in one pool of Moni-trol II control serum with an ACP 5040. In figure $3 \mathrm{~b}$ increasing increments of 2 standard deviations, in figure $3 \mathrm{c}$ of 3 standard deviations are added. The standard deviation is calculated from the data in figure $3 \mathrm{a}$. Further details are reported elsewhere (3).

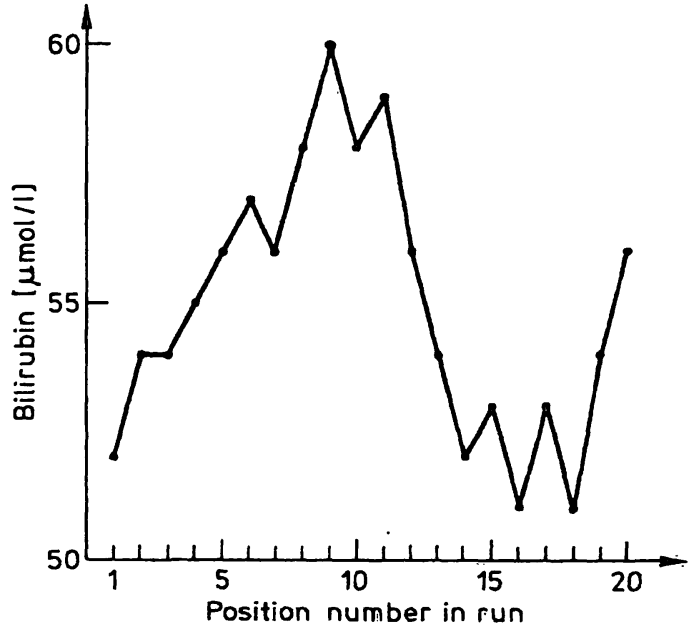

Fig. 4. Run of 20 determinations of the bilirubin concentration in one pool of Hyland control serum with a $30^{\circ} \mathrm{C}$ version of the ACA (2).

could no longer be detected after replacement of the instrument.

The data from one phosphate run (fig. 5a) were taken by chance from a set of 12 runs which were all judged to be more or less normally distributed about the mean after an initial superficial inspection. Trends of 1,2 and 3 standard deviations were simulated as explained above (fig. $5 \mathrm{~b}-\mathrm{d}$ ). Visually a distinct trend could be noticed if a total increment of 3 standard deviations was used (fig. $5 \mathrm{~d}$ ). In this case, however, the r-ratio still did not suggest a trend (tab. 2 ) as in the simulation experiment reported above. This discrepancy is caused by the $8^{\text {th }}$ value. Although the $8^{\text {th }}$ value (fig. $5 \mathrm{~d}$ ) lies inside the lower $3 \mathrm{~s}$-line, it appears not to belong to the same population of data. Since this value was outside the $2.385 \cdot \mathrm{s}$-line, it was considered to be an outlier according to the criteria mentioned under methods.
After elimination of the $8^{\text {th }}$ value in figure 5 very low r-values below the discriminating value of 0.650 were obtained (tab. 2). The data from figure $5 \mathrm{a}$ where no artificial trend was included, led to a $r-$ ratio of 0.54 suggesting that a trend may already be present. Such a trend now exists between the second and eight value (according to the run test discussed later).

\section{Discussion}

Sometimes, identical figures for within-run and between-days imprecision are reported in the literature without further comment. This situation can occur if the data for the between-days imprecision are taken from samples positioned immediately after the calibration, and significant drift effects or outliers are inherent to segments from which the data are used to estimate the within-run imprecision.

Several statistical tests for the detection of trends are listed in table 3. Riddick et al. recommended the well known cumulative sum technique (cusum technique) because it has a higher efficiency in drift-detection than the average and range charts (18). Cembrowski

Tab. 3. Statistical tests for the detection of trends

1. Operational research methods

1.1 Cusum technique

1.2 Trigg's monitoring method

2. Other statistical methods

2.1 Chi square test

2.2 Run test

2.3 Analysis of variance (F-test)

2.4 Application of the regression model 


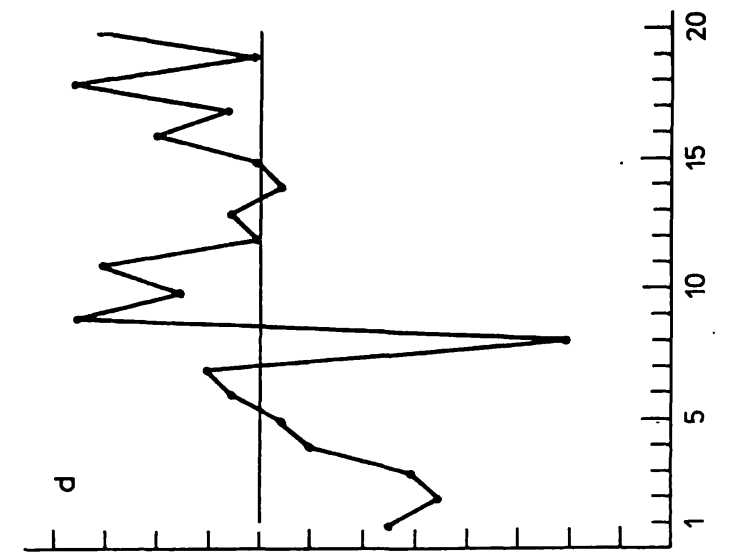

总

言通

至品

กั

齿

ลิ่

纯

胥

.

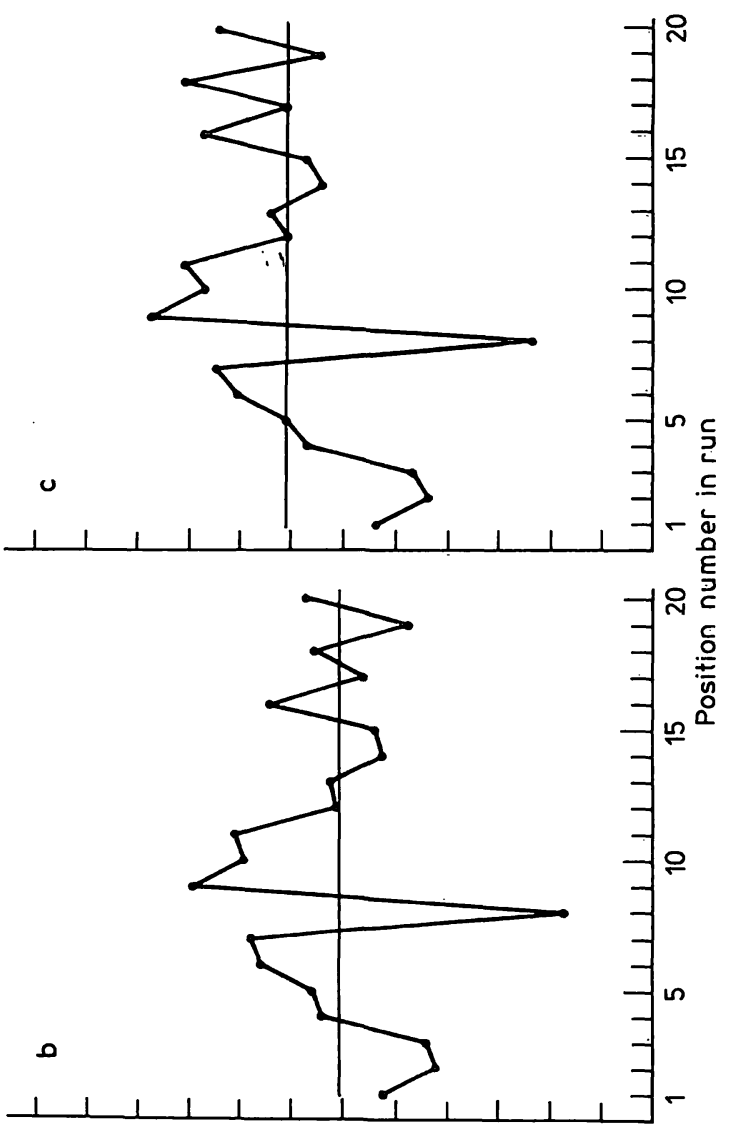

용.

苞

年

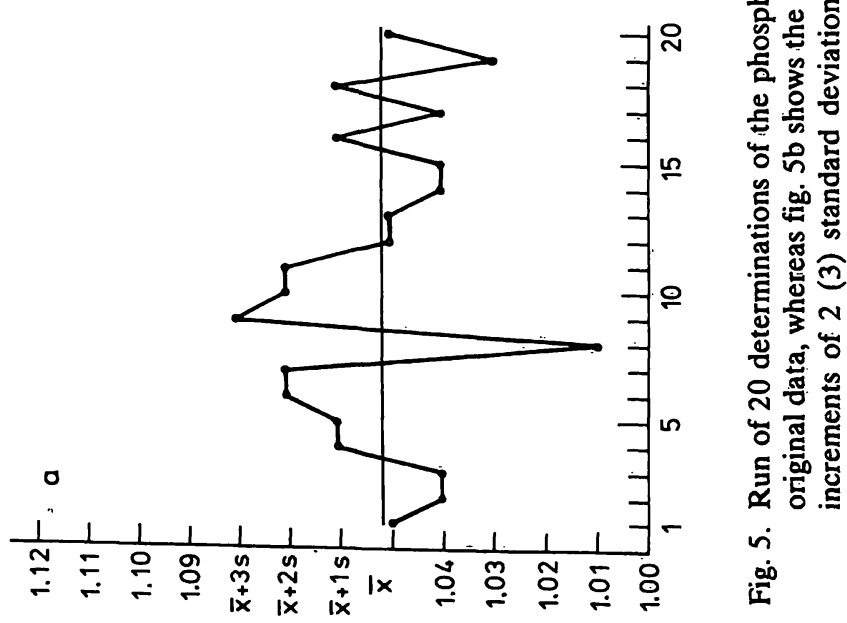

[1/loww] snjoydsoyd ग!UDbJouI et al. (19), however, pointed out that the "out-ofcontrol" situations are still somewhat intuitive with the cusum technique, and therefore, proposed Trigg's method for trend analysis. This must be optimized for the particular laboratory application by choice of appropriate smoothing constant and analysis frequency. These authors have shown by simulation studies that Trigg's technique has similar sensitivity to that of the cusum method.

The operational research methods give an earlièr warning of the existence of a systematic trend than the other methods listed in table 3 . The chi square test was recommeñded by Gindler (20) and the analysis of variance method by Riddick et al. (18), who compared several variances derived from 2 different serum pools.

A run is a sequence of elements of the same kind (e. g. of the same sign + or - ). The length of a run is given by the number of elements defining the run. Runs of points $x_{i}$ can be defined by their location relative to the median; they can be directed up and down (This statistical term is not identical with an analytical run mentioned above).

According to Gooszen (21) the run test is not very sensitive, especially in a short series of results. "Even in the larger series of 20 control determinations the run test often fails to reveal systematic influences". Problems may occur when there is a set of equal numbers around the median (called a tie). In such cases several possibilities must be considered as outlined by Gooszen (21).

A systematic error can be suspected if a run of 7 (8) is observed in a set of $22(30)$ data with a confidence probability of $95 \%$ (22). It should be considered that run tests indicate not only drift effects but also dependencies between successive measurements (aŭtocorrelation).

For trends, the regression model can also be applied. It must be tested whether the slope of the regression line significantly deviates from zero. This procedure is very sensitive to outliers, especially at the beginning or the end of the series.

Whereas all these tests are able to detect trends, they are relatively weak, or incapable of identifying fluctuations.

The r-ratio test is the only test among those mentioned above which indicates uni- and bidirectional trends. However this test appeared relatively ineffective in the presence of a sudden change (outlier) in a data set (because of the assumption of constant mean values for successive pairs). If an error hạs oc̣curred and was recognized, the mêasurement must 
be rejected irrespective of its magnitude. This includes values which are "flagged" in some way on the printout (as e. g. being out of range of an instrument) or values which are obtained when the instrument audibly or visually indicates a questionable result. In many cases, however, only a suspicion arises and then a test of significance should be applied.

Several tests sensitive to outliers are summarized in table 4. A well known test of significance for detect-

Tab. 4. Statistical tests for the detection of outliers (inhomogenities)

\begin{tabular}{lll}
\hline Test name & $\begin{array}{l}\text { Calculation of s } \\
\text { from the same } \\
\text { sample required }\end{array}$ & References \\
\hline 1. r-test & yes & $\begin{array}{l}\text { Nalimov (8) } \\
\text { Rasch et al. (11) } \\
\text { Gottschalk (9) }\end{array}$ \\
2. Dixon-test & no & $\begin{array}{l}\text { Dixon (12) } \\
\text { Sachs (4) } \\
\text { Documenta Geigy (13) }\end{array}$ \\
3. Grubbs test & yes & $\begin{array}{l}\text { Grubbs (16, 17) } \\
\text { Healy (15) }\end{array}$ \\
4. Healy test & no & \\
\hline
\end{tabular}

\section{References}

1. Kolmogorov, A. (1941) Ann. Math. Statist. 12, 461-463.

2. Lillefors, H. W. (1967) J. Am. Statist. Assoc. 62, 399-402.

3. Haeckel, R. (1972) this j. 10, 235-242.

4. Haeckel, R. \& Oellerich, M. (1980) Mitteilungen Dt. Ges. Klin. Chem. 11, 74-95.

5. Haeckel, R., v. Boroviczeny, K. G., Keller, H., Knedel, M., Koss, H. J., Liebegall, M. A. \& Sonntag, O. (1980) Mitteilungen Dt. Ges. Klin. Chem. 11, 195-231.

6. Hald, A. (1952) Statistical Theory with Engineering Applications J. Wiley \& Sons, London, 4th ed., 357-359.

7. Hart, B. I. (1942) Ann. Math. Stat. 13, 445-447.

8. Nalimov, V. V. (1963) Appliçation of mathematical statistics to chemical analysis, Pergamon Press; Oxford 1-294.

9. Gottschalk, G. (1966) Einführung in die Grundlagen der chemischen Materialprüfung. S. Hirzel-Verlag, Stuttgart, $1-188$.

10. Haeckel, R. (1975) Qualitätssicherung im medizinischen Laboratoriumm, Deutscher Ärzteverlag GmbH; Köln, 182183.

11. Rasch, D., Herrendörfer, J., Bock, J. \& Busch, K. (1978) Verfahrensbibliothek, Versuchsplanung und -auswertung. VEB Deutscher Landwirtschaftsverlag Berlin, Band 1-447. ing single outliers is the test described under Methods (6-9). Limits are set at $\bar{x} \pm k$ s (k-values, see l.c. $(8-11))$ and values outside these limits are considered as outliers.

Grubbs $(16,17)$ has given criteria for the simultaneous rejection of several outliers.

The r-ratio test appeared very sensitive to slow alteration, but relatively ineffective in the presence of a sudden change (outlier) in a data set.

In cases where deviations from a normal distribution and the possibility of outliers cannot be tested with one of the methods mentioned, the following procedure is recommended to exclude trend effects before the standard deviation is used as a measure for the within-run imprecision:

As a first step all data should be plotted on a conventional control chart. Gross deviation from normal distribution, distinct outliers or drift effects can be easily detected from visual inspection of the control chart. For an objective detection of drift effects, the $r$-ratio test can be applied, but only in the absence of any outlier.
12. Dixon, W.J. (1953) Biometrics 9, 74-89.

13. Documenta Geigy. Wissenschaftliche Tabellen (1968) 7. Auflage (ed. J. R. Geigy, A. G.), Basle, p. 40.

14. Sachs, L. (1974) Angewandte Statistik, 4. Auflage. Springer Verlag, Berlin, Heidelberg, New York, 218-219.

15. Healy, M. J. R. (1979) Clin. Chem. 25, 657-677.

16. Grubbs, F. E. (1950) Ann. Math. Stat. 21, 27-58.

17. Grubbs, F.E. \& Beck, G. (1972) Technometrics 14,847 , 854 , Corrigendum $15,429$.

18. Riddick, J.H., Flora, R. \& van Meter, O. L. (1972) Clin. Chem. 18, 250-257.

19. Cembrowski, G. S., Westgard, J. O., Eggert, A. A. \& Toren, E. C. (1975) Clin. Chem. 21, 1396-1405.

19. Glinder, E. M. (1975) Clin. Chem. 21, 309-314.

21. Gooszen, J. A. H. (1960) Clin. Chim. Acta 5, 431-438.

22. Hald, A. (1952) Statistical theory with engineering application. John Wiley \& Sons, London, 4th ed., p. 348.

Prof. Dr. R. Haeckel

Inst. f. Laboratoriumsmedizin

Zentralkrankenhaus

St. Jürgenstr.

D-2800 Bremen 1 
